\title{
Correlation Between Homocysteine and Vitamin B12 Serum Level with Vitiligo Severity
}

\author{
Ennesta Asri ${ }^{1}$, Gardenia Akhyar ${ }^{2}$, Rina Gustia ${ }^{3}$ \\ \{ennestaasri@gmail.com ${ }^{1}$, gardeniaakhyar@gmail.com² , rinagustia@gmail.com ${ }^{3}$ \} \\ Department of Dermatology Venereology Faculty Medicine Andalas University \\ RS. Dr. M. Djamil Padang. Indonesia.
}

\begin{abstract}
Vitiligo is an idiopathic disease characterized by depigmented patches on the skin due to loss of melanocytes. Vitiligo is often believed to be present in patients with vitamin B12 deficiency. Vitamin B12 are major determinants of homocysteine levels, and nutritional deficiency in these vitamins results in hyperhomocysteinemia. High levels of homocysteine are suspected to have toxic effects on melanocytes and cause vitiligo. This study aims to know the relation between serum homocysteine and vitamin B12 level with vitiligo severity. This work was an observational study with an analytic cross-sectional study design, consisting of 20 vitiligo patients aged 15-65 years who met inclusion and exclusion criteria. Vitiligo area severity index (VASI) score was calculated, and serum homocysteine and vitamin B12 levels were determined by ELISA method. The mean age of vitiligo patients in this study was $44.55 \pm 14.36$ years and mostly female $(85 \%)$. The most common type is vitiligo Vulgaris (70\%) with the degree of severity based on the VASI score has a mean of $20.33 \pm 25.64$. The mean serum homocysteine level was 10.33 $\pm 10.01 \mu \mathrm{mol} / \mathrm{L}$ and vitamin B12 level was $138.77 \pm 156.07 \mathrm{pmol} / \mathrm{L}$. The association between serum homocysteine and vitamin B12 with a VASI score was not statistically significant. There was no significant correlation between homocysteine levels and serum vitamin B12 with the severity of vitiligo. But in this study see the average vitamin B12 levels are lower than normal values.
\end{abstract}

Keywords: Homocysteine, Vitamin B12, Vitiligo.

\section{Introduction}

Vitiligo is an acquired skin pigmentation disorder, characterized by skin depigmentation in the form of macula hypopigmentation, milky white colored, firmly defined due to loss of function melanocyte epidermis. Vitiligo has several clinical forms, among others: focal, segmental, generalized and universal. There is no difference in incidence between men and women, it can affect the entire age of.[1],[2]

This disorder is estimated to be about $0.5-2 \%$ of the world's population. Prevalence varies, in the United States 1\%, in Denmark 0.38\%, in Japan 2\%, in Egypt 1\%, in the UK 0.24\%, in Russia $0.14 \%$ and India $0.5 \%$. Vitiligo can be found starting at the age of the child, adolescence to adulthood with an onset peak at the age of 10-30 years without racial or gender differences. Patients who seek medical help are mostly women for cosmetic reasons.[1],[3]

Until now the etiology of vitiligo is still unknown, but certain genetic predispositions and some precipitation factors can trigger this disease. Various hypotheses have been suggested that play a role in the pathogenesis of vitiligo, including genetic theory, neural theory, autoimmune 
theory, oxidative stress theory, and melanocytorrhagy theory. The theory of oxidative stress is one of the most popular theories lately [4]. Oxidation accumulation may cause lipid peroxidation, DNA damage or mutation, enzyme activation or inactivation, induced apoptotic pathways, and mediate the release of proinflammatory cytokines. All of the above can cause loss of function, genetic mutation, apoptosis, and tissue damage [5].

Vitiligo patients are also believed to suffer from vitamin B12 deficiency. Vitamin B12 is a major component in the metabolism of homocysteine. Homocysteine is a metabolite produced in metabolic metabolism, thought to have a role in the pathogenesis of vitiligo. High homocysteine levels are thought to have toxic effects on melanocytes and cause vitiligo through the activation of various cytokines and increase free radicals. In addition, it is also suspected through tyrosinase inhibition[6].

It is also suspected that there is a relationship between increased levels of homocysteine and vitiligo severity. Some experts suggest that increased levels of homocysteine in vitiligo patients can be used as a marker of vitiligo severity [7]. Homocysteine has a reactive sulfhydryl group $(-\mathrm{SH})$, this reactive sulfidril group at normal $\mathrm{pH}$ will oxidize into disulfide group (RSSR) and superoxide anion radical $\left(\mathrm{O}^{-} \bullet\right)$. This superoxide anion radical is unstable, very easy to react with oxygen to form $\mathrm{H} 2 \mathrm{O} 2$. So if there is an increase in levels of homocysteine in the blood circulation, then the levels of $\mathrm{H} 2 \mathrm{O} 2$ in the circulation will also increase [8].

There had been a study about the correlation of vitiligo with vitamin B12 and homocysteine levels. There are controversial results from some recent research. Therefore, the researcher conducted this study.

\section{Material and Methods}

\subsection{Study design and research sample}

This research is an observational study with cross-sectional study design that is analytic. The study population was all vitiligo patients who came to the Outpatient Clinic of Dermatology and Venereology department in Dr. M. Djamil Padang hospital. The sample for this study is part of the population that meets the inclusion and exclusion criteria. Including inclusion criteria were vitiligo patients aged 15-65 years and willing to participate in the study. While exclusion criteria were vitiligo patients who received systemic therapy within one month before serum taking, vitiligo patients taking vitamin B12, vitamin B6 and folic acid last one month, smoking, alcohol consumption, coffee and tea consumption $>4$ cups/day and taking methotrexate, anticonvulsant, sulfasalazine, thiazide diuretics, cholestyramine, fibrat acid derivates.

\subsection{Operational definition}

\subsubsection{Vitamin B12 serum Level}

Definition: vitamin soluble in water which is a co-factor in the enzyme methionine synthetase which plays a role in methionine metabolism, its level in serum is measured by the ELISA method. The results are expressed in units of $\mathrm{pg} / \mathrm{ml}$. The examination was conducted at the Biomedical Laboratory of Faculty of Medicine Andalas University, Padang City

Measuring Method: Serum testing using ELISA method 
Measuring Instrument: ELISA reader

Measuring Result: pg/ml

Measuring scale: ratio

\subsubsection{Homocysteine serum level}

Definition: An amino acid which is an intermediate product in methionine metabolism, its level in serum is measured by the ELISA method. The results are expressed in units of $\mu \mathrm{mol} / \mathrm{L}$. The examination was conducted at the Biomedical Laboratory Faculty of Medicine Andalas University, Padang City

Measuring Method: Serum testing using ELISA method

Measuring Instrument: ELISA reader

Measuring Result: $\mu \mathrm{mol} / \mathrm{L}$

Measuring Scale: ratio

\subsubsection{Vitiligo Severity}

Definition: The severity of vitiligo as measured by VASI, the VASI score is determined by summing the vitiligo area in the hands unit and the degree of depigmentation in each hand unit examined.

Measuring method: physical examination

Measuring Instrument: study sheet status, VASI score

Measuring Result: score 0-100

Measuring Scale: ratio

\subsection{Research procedure}

The research was conducted in two places, Outpatient clinic Dermatology and Venereology department in Dr. M. Djamil Padang Hospital for clinical examination of vitiligo and blood taking, and Biomedical Laboratory of Faculty of the Medicine Andalas University of Padang for examination serum homocysteine and vitamin B12 level done by ELISA method. This study was conducted for one year from August 2016 - July 2017. This study has acquired ethical clearance permission from the Ethics Committee of the institution.

\subsection{Data Collection technique}

The selection of research subjects was carried out by consecutive sampling, which is the selection of subjects based on the arrival of patients to the Dermatology and Venereology department in Dr. M. Djamil Padang Hospital.

\subsection{Data analysis}

Data processing and analysis are computerized using Statistical Program for Social Sciences (SPSS) 17.0 and presented in tables and graphs. To analyze vitamin B12 and serum homocysteine levels and be associated with vitiligo severity using a Spearman test with significance $(\mathrm{p})<0.05$. 


\section{Results}

The study sample constituted from 20 vitiligo patient attending the Dermatology Venereology outpatient clinic of Dr. M. Djamil Hospital Padang. The mean age of vitiligo

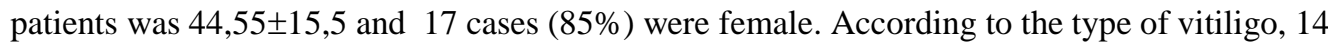
patients $(70 \%)$ were vitiligo vulgaris, three patient $(15 \%)$ were focal vitiligo, and three patients $(15 \%)$ were vitiligo universalis. Based on the degree of severity of vitiligo, in this study obtained the average of $20.33 \pm 25.64$. Comparison of vitiligo patients according to the duration of lesion showed that eight patients (40\%) had recent lesions ranging from $0-10$ years $(40 \%), 6$ patients $(30 \%)$ had duration 11-20 years, 3 patients (15\%) had duration 21-30 years, 2 patient (10\%) had a duration $31-40$ years and 1 patients (5\%) had duration 41-50 years.

The mean serum homocysteine level of the study subjects was $10.33 \pm 10.01 \mu \mathrm{mol} / \mathrm{L}$, with a mean of $8.04 \mu \mathrm{mol} / \mathrm{L}$. The mean serum vitamin B12 level was $138.77 \pm 156.07 \mu \mathrm{mol} / \mathrm{L}$, with a mean of $77.16 \mu \mathrm{mol} / \mathrm{L}$

Table 1. Correlation between homocysteine levels and vitiligo severity

\begin{tabular}{lll}
\hline & & Homocysteine Level \\
\hline VASI Score & $\mathrm{R}$ & 0,057 \\
& $P$ & 0,812 \\
& $\mathrm{~N}$ & 20 \\
\hline
\end{tabular}

In table 1. can be seen correlation coefficient between serum homocysteine level with VASI score is 0,057 with $\mathrm{p}$-value $=0,812$, this means there is a weak correlation between homocysteine level with VASI score. Statistically the correlation is not significant $(\mathrm{p}=0,812)$ because $\mathrm{p}$ value $>0,05$.

Table 2. Correlation between serum vitamin B12 levels and vitiligo severity

\begin{tabular}{lll}
\hline & & Vitamin B12 level \\
\hline VASI Score & $\mathrm{R}$ & 0,131 \\
& $P$ & 0,582 \\
$\mathrm{~N}$ & 20 \\
\hline
\end{tabular}

In table 2. can be seen correlation coefficient between serum vitamin B12 level with VASI score is 0,131 with value $\mathrm{p}=0,582$, this means there was no significant correlation between serum vitamin B12 level with Vitiligo Area Severity Index score. The statistical correlation is also not significant because of the $\mathrm{p}>0,05$.

\section{Discussion}

Vitiligo is a multifactorial, polygenic disorder, with a complex pathogenesis that is not yet well understood. An association has been suggested between vitiligo and pernicious anemia, with controversial results among studies. Vitamin B12 act as a cofactor for the enzyme homocysteine methyltransferase, and deficiencies vitamin B12 result in hyperhomocysteinemia. 
According to our study, the mean age vitiligo patients were $44,55 \pm 15,47$. Nunes et al., Brazil 2011 gained an average age of vitiligo patients 37.14 years [9]. Reddy in India in 2014 earns the most age over 40 years $(42 \%)$ [10]. In this study, it was seen that the age group 2635 years and $46-55$ years old most suffered from vitiligo. Various literature states that vitiligo can affect all age groups [11]. However, when compared with other age groups there was no significant difference regarding numbers.

In this study, female patients were more than men. This is similar to previous studies that have more women suffering from vitiligo than men. This is presumably because women pay more attention to the disease and appearance than men. In addition, there is a more autoimmune disease in the female population.[12]-[14]. The existence of emotional factors such as fear, shame, and confidence that makes more women come for treatment [15].

There was no significant correlation between homocysteine and vitamin B12 with vitiligo severity. Although mean vitamin B12 level was lower, there is a weak correlation between serum vitamin B12 level with VASI score. The results obtained by Yasar et al., Where there was no significant difference between mean vitamin B12 serum vitiligo patients $(212.9 \pm 81.67)$ and controls $(241,15 \pm 126.23)$ [14]. In contrast to the results from another study, the mean vitamin B12 content of vitiligo patients was lower than the mean serum vitamin B12 content of control patients with $\mathrm{p}<0.01$ although the mean value of vitamin B12 levels was still within normal limits [15].

Yasar et al., findings are not much different, they obtained a mean serum homocysteine level of vitiligo patients respectively of $11.4 \pm 4.6 \mu \mathrm{mol} / 1$ and $9.35 \pm 5.70 \mu \mathrm{mol} / \mathrm{L}$ [14]. In contrast to the results obtained by Hamza et al., In Egypt, the mean serum vitamin homocysteine level of vitiligo patients was $17.77 \pm 7.72 \mu \mathrm{mol} / \mathrm{L}$ [13]. Similarly, studies conducted by Singh et al., In India found that the mean serum homocysteine level of vitiligo patients was $30.8 \pm 6.5$ $\mu \mathrm{mol} / \mathrm{L}$. Vitiligo serum homocysteine levels were also found by Agarwal et al., India in 2015, $15.39 \pm 7.2 \mu \mathrm{mol} / \mathrm{L}[15]$.

The differences in the results of this study are due to differences in research sites, ethnicity, and lifestyle. Homocysteine and vitamin B12 levels may differ between ethnicities, but the difference is rather small among ethnic groups living in the same area and consuming the same kind of food. In this study the research samples are all from the Minang ethnic who live in Padang and around them. Therefore different results are obtained with research conducted in India and in Egypt [7],[13]. Increased levels of homocysteine are multifactorial conditions, may be affected by diet and lifestyle, genetic abnormalities of homocysteine metabolism and certain drugs. Researchers have excluded dietary, lifestyle and pharmaceutical factors on screening research subjects, but did not rule out genetic factors. For that, we need further research by considering the genetic polymorphism of vitiligo patients.

\section{Conclusion}

There was no significant correlation between homocysteine levels and serum vitamin B12 with the severity of vitiligo. But in this study, the mean vitamin B12 levels are lower than normal values.

\section{References}

[1] Bilal A, Anwar I. Guidelines for the management of vitiligo. JPAD. pp. 68-78 (2014) 
[2] Birlea SA, Spritz RA, Norris DA. Vitiligo. In: Wolff K, Goldsmith LA, Katz SI, Gilchrest BA, Paller AS, Leffel DJ,editors. Fitzpatrick's dermatology in general medicine. Vol.8, pp. 792-803. McGraw-Hill, New York (2012)

[3] Gawkrodger DJ, Ormerod AD, Shaw L, Mauri-Sole I, Whitton ME, Watts MJ, et al. Guideline for the diagnosis and management of vitiligo. BJD. pp. 1051-76 (2008)

[4] Choi D, Isadeh P, Hamzavi IH.Vitiligo: a review of the pathogenesis. EWDS. pp. 145-58 (2014)

[5] D'Angelo A, Selhub J. Homocysteine and thrombotic disease. Blood. pp.1-11 1997

[6] Glassman SJ. Reactive oxygen species and vitiligo. In: Laher I, editor. System biology of free radicals and antioxidants. pp. 3677-94. Springer-Verlag, Berlin. (2014)

[7] El-Dawela RE, Abou-elfetouh S. Relationship between homocysteine,vitamin B12, folic acid levels and vitiligo. J Appl Sci Res. pp. 5528-35. (2012)

[8] Jacobsen DW. Hyperhomocysteinemia and oxidative stres. Arterioscler Thromb Vasc Biol. pp. 1182-4 (2000)

[9] Nunes DH, Esser LMH. Vitiligo epidemiological profile and the association with thyroid disease. An Bras Dermato. pp. 241-8. (2011)

[10] Reddy J. A survey on the prevalence of vitiligo in Bangalore city, India. IJPMBS. pp. 3546.(2014)

[11] Kruger C, Schallreuter KU. A review of the worldwide prevalence of vitiligo in children/ adolescents and adults. IJD. pp. 1-7. (2012)

[12] Shajil E, Agrawal D, Vagadia K, Marfatia Y, Begum R. Vitiligo: Clinical profiles in Vadodara, Gujarat. Indian J Dermatol. pp.100-4. (2006).

[13] Hamza AM, Farid CI, El-sayed ET, Kadeeb HAR. Assessment of serum homocysteine level in patients with nonsemental vitiligo. Egypt J Dermatol Venerol. pp. 59-64 (2015).

[14] Yasar A, Gunduz K, Onur E, Calkan M. Serum homocysteine, vitamin B12, Folic acid levels and methylenetetrahydrofolate reductase (MTHFR) gene polymorphism in vitiligo. Disease Markers. pp.85-9. (2012).

[15] Agarwal S, Mendiratta V, Chander R, J Anju, Yadav P. Study of serum level of vitamin B12, folic acid and homocysteine in vitiligo. Pigment International. pp. 76-80. (2015). 